\title{
Mechanical Properties and Tensile Fatigue of Graphene Nanoplatelets Reinforced Polymer Nanocomposites
}

\author{
Ming-Yuan Shen, ${ }^{1}$ Tung-Yu Chang, ${ }^{2}$ Tsung-Han Hsieh, ${ }^{3}$ Yi-Luen Li, ${ }^{1}$ Chin-Lung Chiang, \\ Hsiharng Yang, ${ }^{2}$ and Ming-Chuen Yip ${ }^{1}$ \\ ${ }^{1}$ Department of Power Mechanical Engineering, National Tsing Hua University, Hsinchu 30013, Taiwan \\ ${ }^{2}$ Graduate Institute of Precision Engineering, National Chung Hsing University, Taichung 40227, Taiwan \\ ${ }^{3}$ Department of Mold and Die Engineering, National Kaohsiung University of Applied Science, Kaohsiung County 80778, Taiwan \\ ${ }^{4}$ Department of Safety, Health and Environmental Engineering, Hung Kuang University, Taichung 43302, Taiwan
}

Correspondence should be addressed to Ming-Chuen Yip; mcyip@pme.nthu.edu.tw

Received 31 May 2013; Accepted 9 September 2013

Academic Editor: Kyong Yop Rhee

Copyright (c) 2013 Ming-Yuan Shen et al. This is an open access article distributed under the Creative Commons Attribution License, which permits unrestricted use, distribution, and reproduction in any medium, provided the original work is properly cited.

\begin{abstract}
Graphene nanoplatelets (GNPs) are novel nanofillers possessing attractive characteristics, including robust compatibility with most polymers, high absolute strength, and cost effectiveness. In this study, GNPs were used to reinforce epoxy composite and epoxy/carbon fiber composite laminates to enhance their mechanical properties. The mechanical properties of GNPs/epoxy nanocomposite, such as ultimate tensile strength and flexure properties, were investigated. The fatigue life of epoxy/carbon fiber composite laminate with GPs-added $0.25 \mathrm{wt} \%$ was increased over that of neat laminates at all levels of cyclic stress. Consequently, significant improvement in the mechanical properties of ultimate tensile strength, flexure, and fatigue life was attained for these epoxy resin composites and carbon fiber-reinforced epoxy composite laminates.
\end{abstract}

\section{Introduction}

Graphene nanoplatelets (GNPs) are a novel nanofillers including single or multilayers of a graphite plane which possesses exceptional functionalities, high mechanical strength (1 TPa in Young's modulus and $130 \mathrm{GPa}$ in ultimate strength), and chemical stability, for the following reasons: their abundance in nature and thus their cost effectiveness and their extremely high-specific surface area, which carries high levels of transferring stress across interface and provides higher reinforcement [1-8] than carbon nanotubes.

Graphene nanoplatelets (GNPs) are platelet-liked graphite nanocrystals with multigraphene layers. In general, a high contact area between polymer and nanofiller maximizes stress transfer from polymer matrix to nanofillers. Therefore, GNPs can be expected to exhibit better reinforcement than CNTs in polymer composites, due to their ultrahigh aspect ratio $(600-10,000)[9-13]$ and higher surface constant area. The GNPs planar structure provides a $2 \mathrm{D}$ path for phonon transport, and the ultrahigh surface area allows a large surface contact area with polymer resulting in enhancement of the composite thermal conductivity [14-16]. However, the large surface area between GNPs which is NGP planar nanosheets results in large Van der Waals forces and strong $\pi-\pi$ interactions [17-19]. Thus, the performance of graphenebased polymer composites is limited by the aggregation and stacking of NGP sheets. Since the physicochemical properties of aggregated GNPs are similar to those of graphite with its relatively low-specific surface area, the performances of GNPs will suffer significantly from reduced performance. This is an important issue if NGP potential as a polymer composite reinforcing materials is realized $[20,21]$.

Epoxy is widely applied in advanced carbon fiber reinforce plastic (CFRP) due to their good mechanical performance, process-ability, compatibility with most fibers, chemical resistance, wear resistance, and low cost. However, these materials are relatively brittle, which is detrimental to the interlaminar properties between matrix and reinforcement. The addition of CNTs or GNPs to improve the interfacial strength of laminates has been demonstrated. Besides, the 
great potential to increase the mechanical properties of thermoset resins and their fiber-reinforced composites as using CNTs and GNPs as fillers.

To the best of our knowledge, very few studies have so far been reported on the fabrication of graphene nanoplatelets (GNPs) reinforced CFRP composites using manufacturing of prepregs [22]. GNPs are difficult to process because of the issues associated with agglomeration and lack of interfacial interactions with polymers. None of the previous studies, nevertheless, have given due attention to the influence of adding GNPs on the solvent type prepreg process. Therefore, it is necessary to understand the role of adding GNPs into the matrix material, which will largely affect the impregnation of fibres and prepreg processing conditions.

In this study, various amounts of graphene nanoplatelets (GNPs) were uniformly dispersed in epoxy resin (i.e., 0, $0.25,0.5,1$, and $1.5 \mathrm{wt} \%$ ) and prepared the GNPs/epoxy nanocomposites. Mechanical properties of the nanocomposite, including ultimate tensile, flexural strength, and flexural modulus, were investigated.

In addition, the solution of epoxy resin that contained highly and evenly dispersed GNPs permeated a carbon fiber cloth was used to prepare the carbon fiber/epoxy composite laminates. The process was used to investigate if GNPs improved the tensile fatigue of carbon fiber reinforced epoxy resin composite laminates.

Finally, The fracture surface of the specimen was investigated using scanning electron microscopy (SEM) to determine the dispersion of the GNPs in the composites.

\section{Experimental}

2.1. Preparation of GNPs/Epoxy Resin Solution. The unmodified graphene nanoplatelets, GNPs (Xiamen Knano Graphene Technology Co., Ltd., China) with a thickness of 5-25 nm were used for reinforcement in this study. The GNPs/Methyl ethyl ketone (MEK) solution was stirred for 10 minutes using a homogenizer. The solution was then vibrated by ultrasonication for 90 minutes to enable the GNPs to disperse uniformly throughout the methyl ethyl ketone solution.

The GNPs/MEK solution was mixed with epoxy resin (EPO-622 Epoxy Resin, Epotech Composite Co., Ltd, Taiwan) for 90 minutes using a mechanical mixer and then vibrated by ultrasonication for 90 minutes to enable the GNPs to disperse uniformly throughout the epoxy solution. A schematic illustration of the fabrication of the GNPs/epoxy resin is shown in Figure 1(a).

\subsection{Preparation of GNPs/Epoxy Nanocomposites. The GNPs/} epoxy resin solution was placed in a vacuum heating oven and vacuum pumping was performed for 5 minutes to eliminate air bubbles. The resin solution was poured into molds and then placed on a hot press machine to form the GNPs/epoxy nanocomposites (pressed at $1500 \mathrm{psi}$ and $150^{\circ} \mathrm{C}$ for 30 minutes). The nanocomposites were then placed in a heating oven at $140^{\circ} \mathrm{C}$ for 3 hours to eliminate the internal stress (postcure). A schematic illustration of the fabrication of the GNPs/epoxy nanocomposite is shown in Figure 1(b).

\subsection{Preparation of GNPs/Epoxy/Carbon Fiber Composite Laminates}

2.3.1. Impregnation of Carbon Fiber Fabric with Epoxy Resin (Prepreg). A piece of $3 \mathrm{k}$ carbon fiber fabric of the desired dimensions was placed on a release paper and the GNPs/epoxy resin solution was evenly permeated on it. The carbon fiber fabric with uniformly dispersed GNPs/epoxy resin (prepreg) was then placed in a heating oven to expose at $83^{\circ} \mathrm{C}$ for three hours to evaporate all of the solvent.

2.3.2. Hot Press Molding and Postcuring. Thirteen pieces of prepregs were piled in a mold and placed on a hot press machine to prepare a GNPs/epoxy/carbon fiber composite laminate (pressed at $1500 \mathrm{psi}$ and $150^{\circ} \mathrm{C}$ for $30 \mathrm{mins}$ ). The composite laminate was then placed in a heating oven at $140^{\circ} \mathrm{C}$ for three hours to eliminate the internal stress of laminate (post-cure) [23]. A schematic illustration of the fabrication of the composite laminate is shown in Figure 1(c).

\subsection{Experimental Process}

2.4.1. Morphology of GNPs. The microstructure of GNPs was analyzed using transmission electron microscopy (TEM) and field emission scanning electron microscopy (FESEM).

2.4.2. Experimental Process of GNPs/Epoxy Nanocomposites. Graphene nanoplatelets (GNPs) reinforced epoxy composite with four proportions of GNPs (i.e., $0.25,0.5$, 1 , and $1.5 \mathrm{wt} \%$ ) were fabricated. The mechanical properties of the nanocomposites, such as ultimate tensile strength, flexural strength, and flexural modulus, were investigated.

The fracture surface of the specimen was investigated using SEM to determine the dispersion of the GNPs in the nanocomposites.

2.4.3. Experimental Process of Composite Laminates. GNPs reinforced epoxy/carbon fiber composite laminates with $0.25 \mathrm{wt} \%$ GNPs added were fabricated. Tensile fatigue tests were conducted in a load control mode at a frequency of $4 \mathrm{~Hz}$. As shown in Figure 2, the ratio of the minimum to maximum stress in a cycle was $0.1(R$-ratio $=+0.1)$. During the fatigue life measurements, the specimens were subjected to cyclic loading until the final fracture, at which point the specimen was completely separated into three pieces. The samples were tested with four stress levels at $80 \%-95 \%$ of their static tensile strength.

The fracture surface of the specimens was investigated using SEM to determine if the GNPs would prevent the formation of pores in the laminates and makes GNPs effective in delivering stress to improve the tensile fatigue of composite laminates.

\section{Results and Discussion}

3.1. Morphology Analysis of GNPs. The TEM morphology of the GNPs is shown in Figure 3(a); the SEM morphology of the GNPs is shown as a platelet shape with nanosheet dimensions 


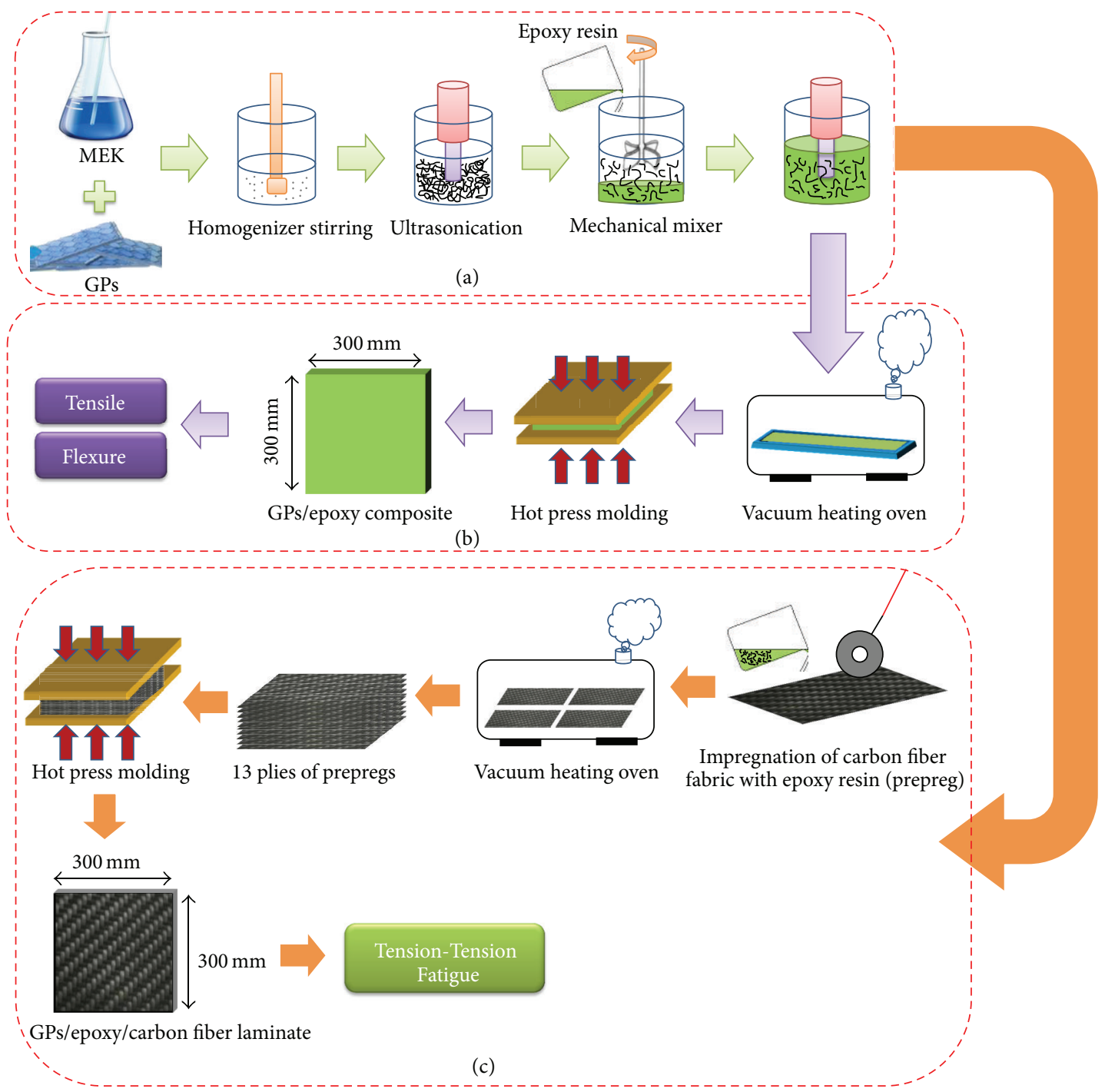

FIGURE 1: A schematic illustration of the fabrication of composites: (a) GNPs/epoxy resin solution; (b) GNPs/epoxy nanocomposites; (c) GNPs/CFRP composite laminates.

of more than $5 \mu \mathrm{m}$ and thickness of approximately 5-25 $\mathrm{nm}$; as shown in Figure 3(b), the GNPs possess a large aspect ratio, which is a central factor in enhancing the contact area with the composite. The TEM and SEM images also show the surface morphology of GNPs, which is considerably different compared to carbon black, carbon nanotubes, and graphite. The images indicate that the GNPs nanosheets are thin at the nanoscale. However, SEM and TEM images showed that GNPs aggregated to form bundles, because of Van der Waal forces.

3.2. Tensile Strength of GNPs/Epoxy Nanocomposites. Figure 4 and Table 1 show the ultimate tensile strength of the nanocomposites without and with the four proportions of GNPs contents. The tensile strength of the nanocomposite with GNPs added at $0.25 \mathrm{wt} \%$ shows the best enhancement

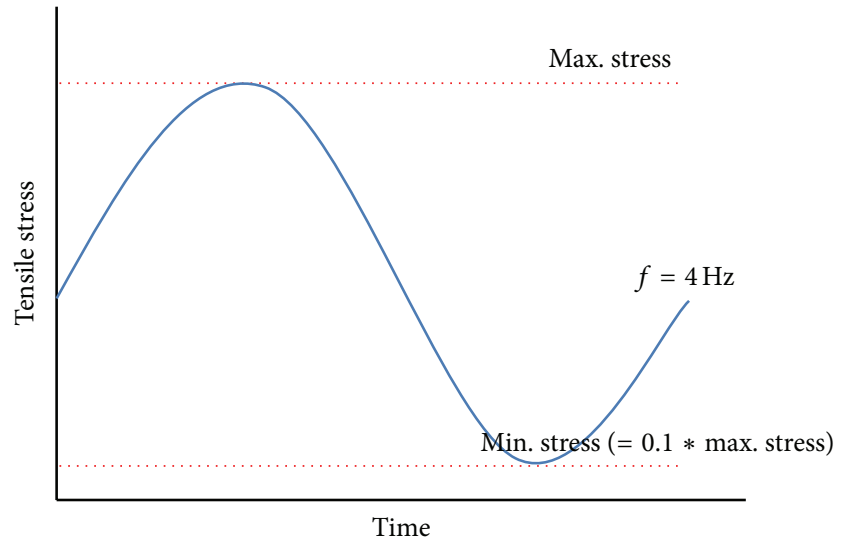

FIGURE 2: Schematic diagram of tension-tension cyclic loading in fatigue tests. 
TABLE 1: Mechanical properties of GNPs/epoxy nanocomposites.

\begin{tabular}{lccccc}
\hline Test item (unit) & \multicolumn{3}{c}{ GNPs contents (wt\%) } & 0.5 & 1.0 \\
\hline TS $(\mathrm{MPa})$ & 54.89 & $66.00(+20 \%)$ & $61.11(+11 \%)$ & $55.59(+1 \%)$ & $51.82(-6 \%)$ \\
FS (MPa) & 105.89 & $115.46(+9 \%)$ & $107.07(+1 \%)$ & $104.48(-1 \%)$ & $96.54(-9 \%)$ \\
FM $(\mathrm{GPa})$ & 2.22 & $2.49(+12 \%)$ & $2.50(+12 \%)$ & $2.53(+14 \%)$ & $2.63(+19 \%)$ \\
\hline
\end{tabular}

GNPs/epoxy nanocomposites, TS: tensile strength, FS: flexural strength, FM: flexural modulus.

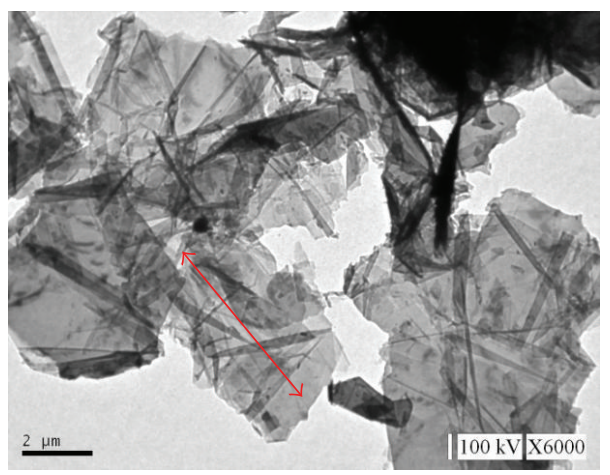

(a)

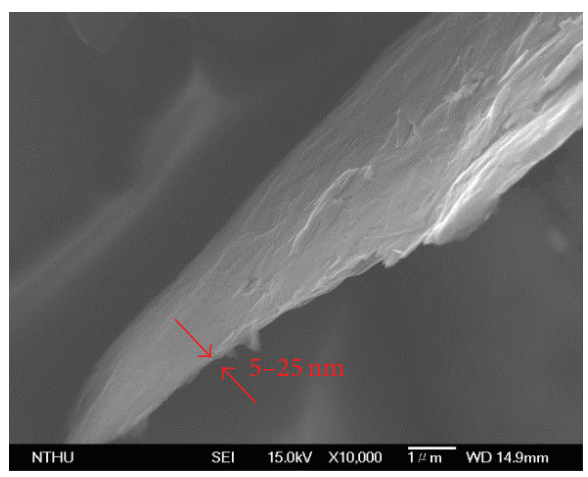

(b)

Figure 3: Morphology of GNPs. (a) TEM image; (b) SEM image.

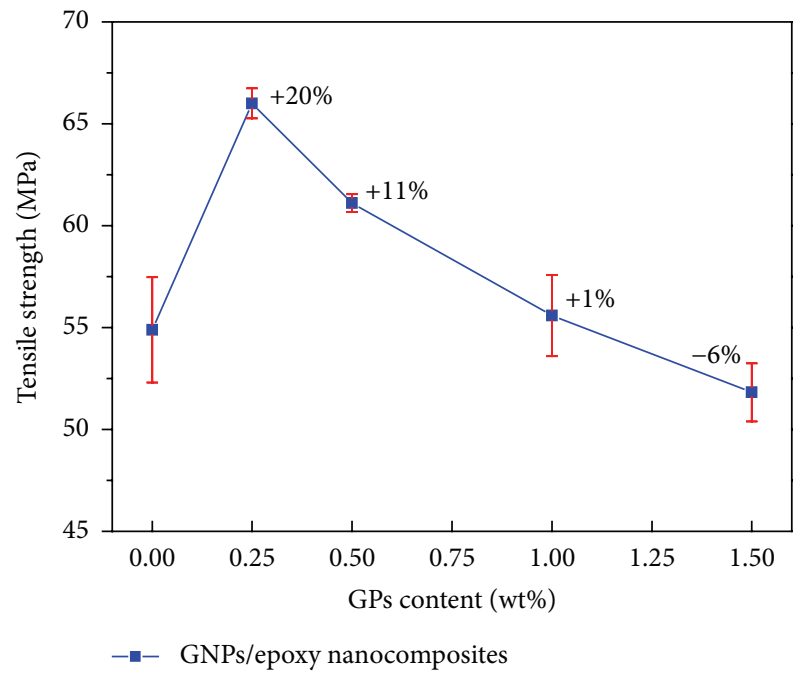

FIGURE 4: Tensile strength of GNPs/epoxy nanocomposites.

(20\%) compared to the composite without any GNPs added. The strength begins to degrade at the $0.5 \mathrm{wt} \%$ GNPs loading.

The mobility of polymer chains was restricted because of the dispersion of nanofillers under low content. The high aspect ratio, high modulus, strength of nanofillers, and robust interfacial adhesion between the nanofillers and matrix also contributed to the reinforcement. However, the decrease in strength with high nanofiller content can be attributed to the following two effects. (1) nonuniform dispersion of the nanofillers in higher loading systems, acoustic cavitation is one parameter for nanoparticle dispersion under low content. (2) Voids might also have decreased the strength. Choi et al.

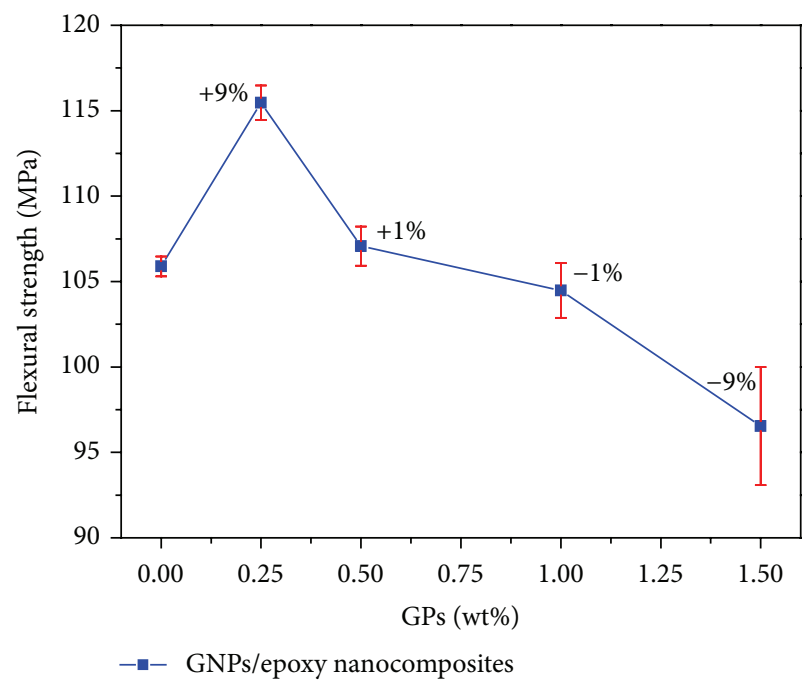

FIGURE 5: Flexural strength of GNPs/epoxy nanocomposites.

reported that few voids were produced during the fabrication process and that voids increased with higher nanoparticle content [24-26].

3.3. Flexure Test Analysis of GNPS/Epoxy Nanocomposites. Figure 5 and Table 1 indicate that the flexural strength of composites without added GNPs is approximately $105.89 \mathrm{MPa}$. The flexural strength of the GNPs-added reinforced composite was $9 \%$ higher at $115.46 \mathrm{MPa}$ composite without added GNPs when the GNPs content was 0.25 wt $\%$.

However, the decrease of strength with higher GNPs content $(0.5 \mathrm{wt} \%)$ can be attributed to the following two 


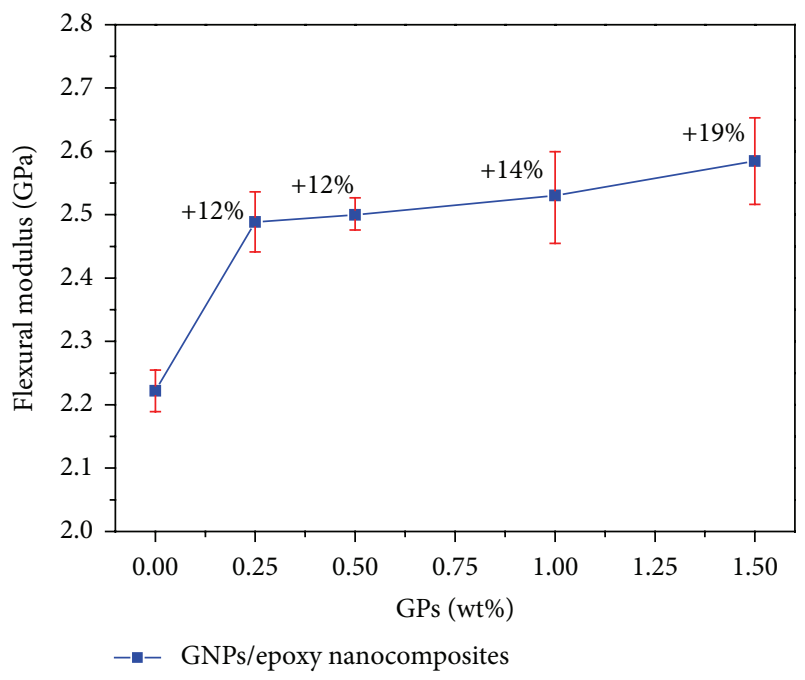

Figure 6: Flexural modulus of GNPs/epoxy nanocomposites.

effects: (1) the properties of GNPs rapidly devolve as sheets aggregate, because aggregated sheets behave like micrometersize fillers with relatively low surface area. (2) The GNPs agglomerates would form steric obstacles, restricting polymer to flow into the agglomerates, and resulting in the formation of holes and voids between GNPs and epoxy [27].

Moreover, Figure 6 and Table 1 show the flexural modulus measured from the flexural test of GNPs/epoxy nanocomposites, which is plotted as a function of GNPs content. The modulus grew rapidly with increasing GNPs content. When the GNPs content increased to $1.5 \mathrm{wt} \%$, the highest flexural modulus was reached, and the enhancement was increased by $19 \%$. In general, the addition of nanoparticles (e.g., GNPs or CNTs), which results in the decrement of mobility of polymer chains, gradually became brittle $[28,29]$ and increased the modulus of the composite.

The aspect ratio of GNPs is an important factor for micromechanical models like Halpin-Tsai model [30, 31] and Mori-Tanaka model [32]. The Shear Lag Model [33] as given by (1a), (1b), and (1c) has been used by Gao and Li [34] to understand the reinforcing ability of nanofiller in polymer composites in terms of their load transfer efficiency:

$$
\begin{gathered}
\sigma_{f}=E_{f} \mathcal{E}\left[1-\left(\frac{\cosh (2 x \lambda \alpha / 1)}{\cos h(\lambda \alpha)}\right)\right], \\
\tau_{i}=\left[\frac{\sin h(2 x \lambda \alpha / 1)}{\cos h(\lambda \alpha)}\right],
\end{gathered}
$$

where

$$
\lambda=\left[\frac{4 G_{m}}{E_{f} \ln \phi_{f}}\right]^{1 / 2}
$$

$\sigma_{f}$ is load transfer efficiency, $\tau_{i}$ is the interfacial shear stress along the filler length, $E_{f}$ is filler modulus, $\varepsilon$ is applied strain, $x$ is the distance from the center of filler, $\alpha$ is filler aspect ratio, $G_{m}$ is shear modulus of the matrix, and $\varphi_{f}$ is the filler volume fraction [35]. Based on the shear lag model, it can be stated that high aspect ratio and high filler modulus facilitate load transfer in fillers $[35,36]$.

3.4. Fracture Surface of GNPs/Epoxy Nanocomposites. The fracture surfaces of the neat epoxy composites (without adding GNPs) and the GNP/epoxy nanocomposites were comparatively examined using SEM. Neat epoxy resin composites exhibited a relatively smooth fracture surface, and the higher magnification SEM image in Figures 7(a) and 7(b) indicates a smooth, mirror-like fracture surface representing the brittle failure of the unfilled epoxy.

As GNPs content increased to $0.25 \mathrm{wt} \%$, considerable corrugation was found in the crevices among the matrix, as shown in Figures 7(c) and 7(d). GNPs cross-linked in the crevices in the corrugation area restrain creviced growth. The static mechanical properties can be enhanced because both the corrugation and GNPs increase the interfacial fraction between the GNPs and matrix.

The strength showed a decrease as GNPs content increased to $0.5,1$, and $1.5 \mathrm{wt} \%$ because the GNPs aggregates would sterically hinder polymer flow, thereby resulting in the formation of defects, as shown in the insert image of Figures $7(\mathrm{e})$ and 7(f). For composites containing GNPs, the existence of holes suggests low adhesion and poor compatibility between the GNPs and matrix, engendering a rapid decrease in the strength of the composites. However, the aggregates particles increased the stiffness of the material and resulted in an increase in the modulus of composites.

\subsection{Tensile Fatigue of GNPs/Epoxy/Carbon Fiber Composite} Laminates. Table 2 presents the experimental results of the fatigue test for the neat and $0.25 \mathrm{wt} \%$ GNPs reinforced epoxy/carbon fiber composite laminate. The normalized ( $\sigma=$ $\left.\sigma_{\max } / \mathrm{TS}, \%\right) S-N$ curve for the neat and GNPs reinforced composite laminates are shown in Figure 8. The results reveal that the fatigue life extended from 1.21 to 5.39 times that of the neat composite laminate at $95 \%$ and $85 \%$ normalized $(\sigma=$ $\left.\sigma_{\max } / \mathrm{TS}, \%\right)$ cyclic stress. At $r_{\max }=370 \mathrm{MPa}$ and $400 \mathrm{MPa}$, the durability of the composite laminate drastically improved to more than 15.30 to 37.07 times with the addition of $0.25 \mathrm{wt} \%$ GNPs, shown as Figure 9. Furthermore, the slopes of the $S-N$ curves of the neat composite laminate were deeper than those of the GNPs-added composite laminate, indicating that the fatigue life of the neat laminate was more sensitive to applied stress levels compared to the GNPs-added composite laminate. The reason for the shift of the $S-N$ slope could be that fractures occur earlier in the neat laminates at all cyclic stresses.

Figures 10(a) and 10(b) illustrate the fracture surfaces of composite laminates after fatigue failure using SEM. CFRP composite laminates under loads lower than the overall static tensile strength were less likely to fracture. Based on the fracture surface observations, the fatigue performance of the laminates was correlated to the formation and expansion of the fatigue failures. Fractures are primarily produced by delamination, which is caused by the interaction between the carbon fiber layer and the resin. Consequent to delamination, 


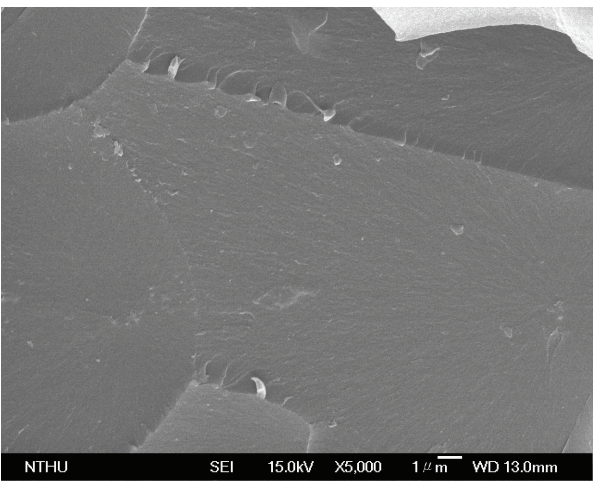

(a)

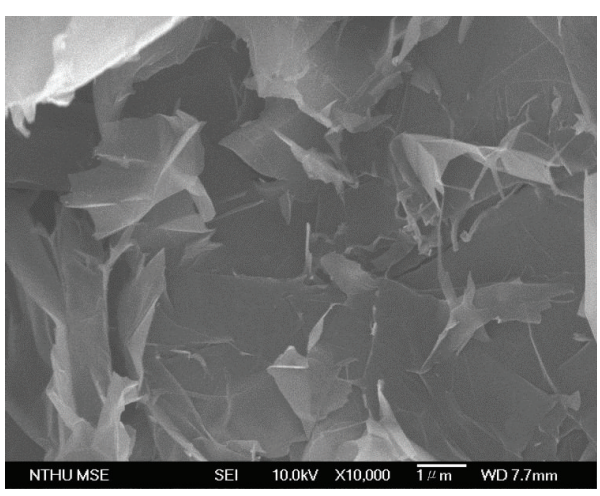

(c)

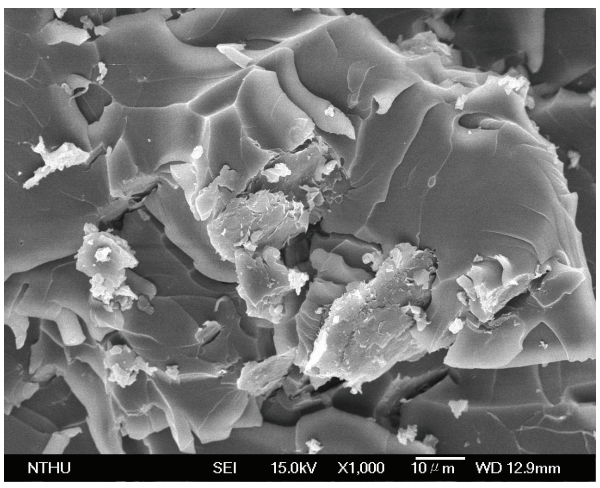

(e)

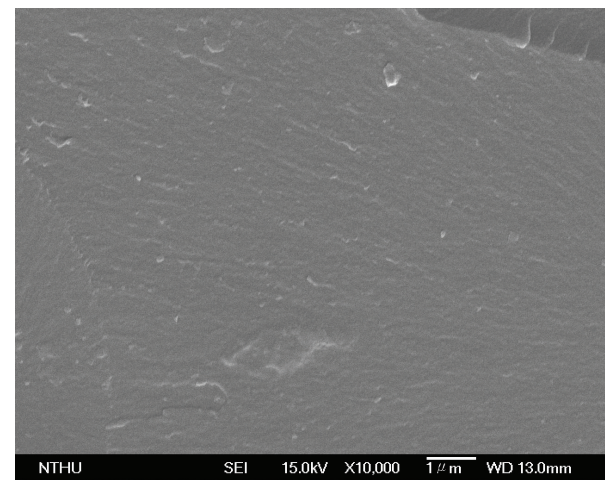

(b)

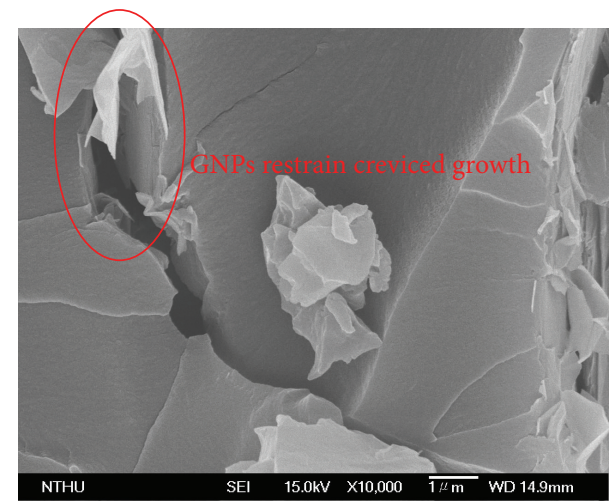

(d)

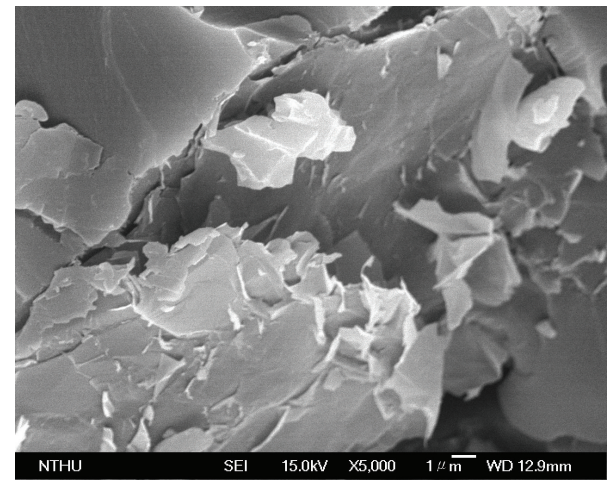

(f)

Figure 7: (a), (b) Fracture surface of neat epoxy composite. (c), (d) Fracture surface of the 0.25 wt\% GNPs/epoxy nanocomposite. (e), (f) Fracture surface of the $0.75 \mathrm{wt} \%$ GNPs/epoxy nanocomposite.

TABLE 2: Loading and life data for CFRP composite laminates with and without GNPs contents.

\begin{tabular}{lccccc}
\hline & \multicolumn{2}{c}{ CFRP composite laminates } & & \\
\multicolumn{1}{c}{0} & \multicolumn{2}{c}{0.25 wt $\%$ (GNPs) } \\
$\sigma_{\max } / \mathrm{TS}$ & $\sigma_{\max }(\mathrm{MPa})$ & Number of cycles to failure & $\sigma_{\max } / \mathrm{TS}$ & $\sigma_{\max }(\mathrm{MPa})$ & Number of cycles to failure \\
\hline $100 \%$ & 419.30 & - & $100 \%$ & 446.38 & - \\
$95 \%$ & 398.34 & 118 & $95 \%$ & 413.61 & 190 \\
$90 \%$ & 377.37 & 13071 & $92 \%$ & 400.55 & 1877 \\
$85 \%$ & 356.41 & 96574 & $90 \%$ & 391.84 & 26000 \\
$82 \%$ & 343.83 & 409975 & $85 \%$ & 370.07 & 334635 \\
\hline
\end{tabular}




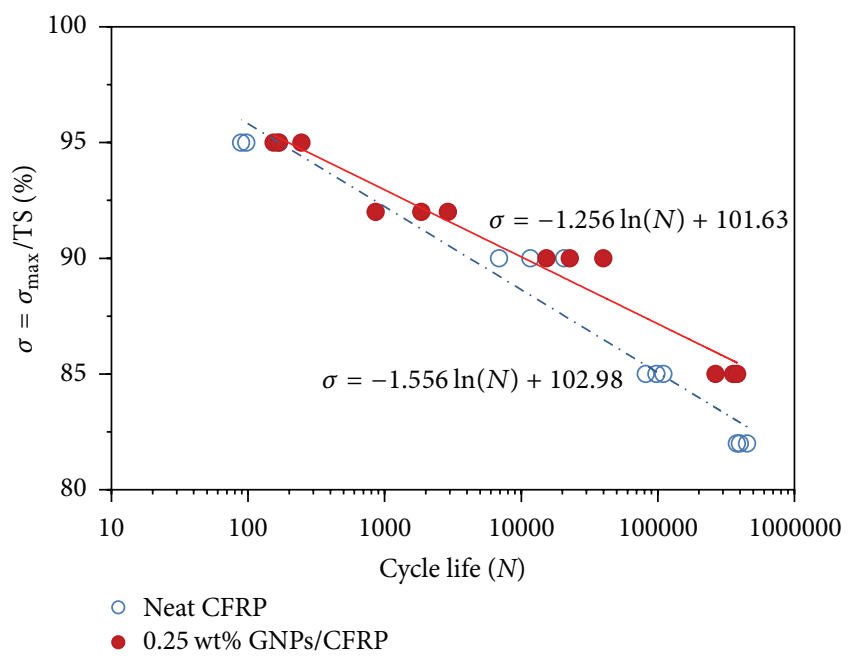

FIgURE 8: Normalized ( $\left.\sigma=\sigma_{\max } / \mathrm{TS}, \%\right) S$ - $N$ curve of the CFRP composite laminates with and without $0.25 \mathrm{wt} \%$ GNPs contents.

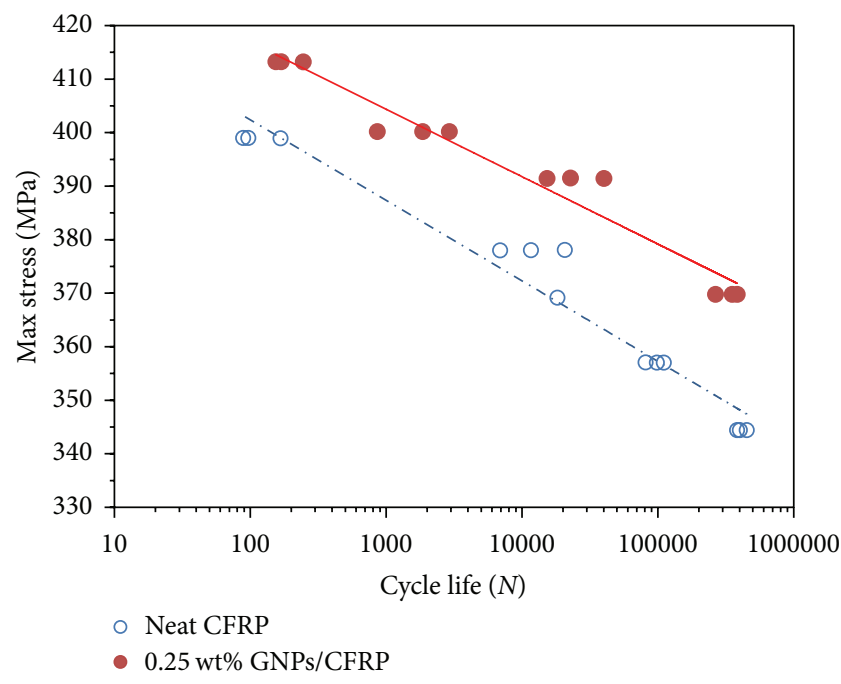

FIGURE 9: $S$-N curve of the CFRP laminates with and without $0.25 \mathrm{wt} \%$ GNPs contents.

stress is concentrated at the fracture site, which gradually accelerates fracture of the carbon fibers and matrix, and leads to the complete fracturing of the laminate surface. Figure 10(a) illustrates a cross-sectional view of the neat composite laminate with fatigue failure. Extracted carbon fibers on the smooth facture surface are clearly observable, implying that the adhesion between the carbon fibers and the resin is weak. Consequently, the carbon fiber layers rapidly disengaged from each other under cyclic loading, causing severe delamination. Figure 10(b) illustrates the fracture surface of $0.25 \mathrm{wt} \%$ GNPs/CFRP composite laminates after fatigue failure. Because of the addition of GNPs, the adhesion between the fibers and resin was significantly improved, thereby reinforcing the adhesion properties between the composite layers. Therefore, embedding GNPs into resin can suppress the formation of microcracks during cyclic loading

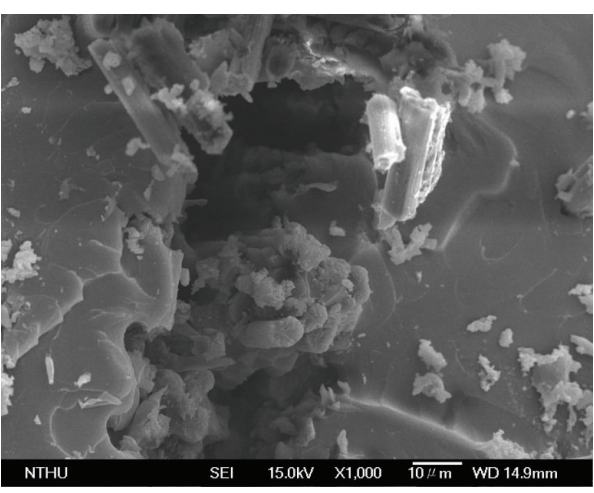

(a)

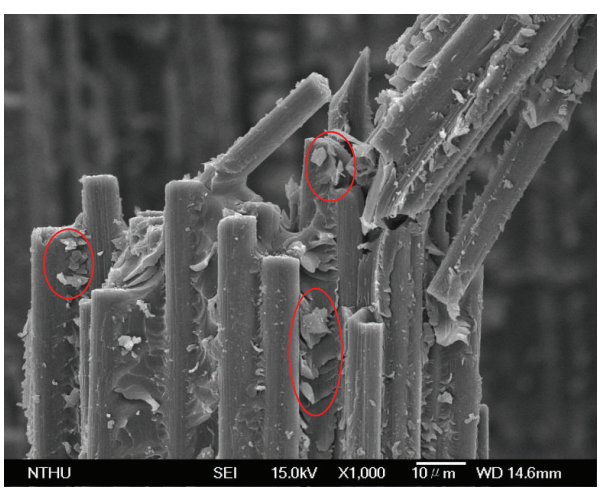

(b)

FIGURE 10: Fracture surfaces of CFRP composite laminates after fatigue failure. (a) Neat CFRP composite laminate; (b) $0.25 \mathrm{wt} \%$ GNPs/CFRP composite laminate.

and prevent the expansion of these cracks, which weakens the effects of delamination, minimizes fractures, and enhances the overall lifespan of CFRP composite laminates.

\section{Conclusion}

The experimental results showed that the mechanical properties of GNPs/epoxy nanocomposites have optimal characteristics with reinforcement through GNPs addition; furthermore, the ultimate tensile strength, flexural strength, and flexural modulus were all improved. Based on the experimental results, adding the present GNPs to the CFRP composite laminates increases fatigue life and provides a considerable reinforcement effect. Therefore, embedding GNPs can restrain creviced growth in the GNPs/epoxy nanocomposites and prevent the expansion of these cracks, which weakens the effects of delamination, minimizes fractures, and enhances the overall lifespan of CFRP composite laminates.

\section{Acknowledgment}

The authors would like to thank the National Science Council, Taiwan, for financially supporting this research under Contracts nos. NSC-102-3113-P-007-009 and NSC-102-2221E-007-039. 


\section{References}

[1] C. Lee, X. Wei, J. W. Kysar, and J. Hone, "Measurement of the elastic properties and intrinsic strength of monolayer graphene," Science, vol. 321, no. 5887, pp. 385-388, 2008.

[2] D. R. Paul and L. M. Robeson, "Polymer nanotechnology: nanocomposites," Polymer, vol. 49, no. 15, pp. 3187-3204, 2008.

[3] Q. H. Zeng, A. B. Yu, G. Q. Lu, and D. R. Paul, "Clay-based polymer nanocomposites: research and commercial development," Journal of Nanoscience and Nanotechnology, vol. 5, no. 10, pp. 1574-1592, 2005.

[4] L. A. Goettler, K. Y. Lee, and H. Thakkar, "Layered silicate reinforced polymer nanocomposites: development and applications," Polymer Reviews, vol. 47, no. 2, pp. 291-317, 2007.

[5] L. Gao, X. Zhou, and Y. Ding, "Effective thermal and electrical conductivity of carbon nanotube composites," Chemical Physics Letters, vol. 434, no. 4-6, pp. 297-300, 2007.

[6] J. Ma, J. Xu, J.-H. Ren, Z.-Z. Yu, and Y.-W. Mai, "A new approach to polymer/montmorillonite nanocomposites," Polymer, vol. 44, no. 16, pp. 4619-4624, 2003.

[7] J. Ma, P. Xiang, Y.-W. Mai, and L.-Q. Zhang, "A novel approach to high performance elastomer by using clay," Macromolecular Rapid Communications, vol. 25, no. 19, pp. 1692-1696, 2004.

[8] J. Ma, Z.-Z. Yu, H.-C. Kuan, A. Dasari, and Y.-W. Mai, "A new strategy to exfoliate silicone rubber/clay nanocomposites," Macromolecular Rapid Communications, vol.26, no. 10, pp. 830833, 2005.

[9] J. Li and J.-K. Kim, "Percolation threshold of conducting polymer composites containing 3D randomly distributed graphite nanoplatelets," Composites Science and Technology, vol. 67, no. 10, pp. 2114-2120, 2007.

[10] W.-G. Weng, G.-H. Chen, D.-J. Wu, and W.-L. Yan, "HDPE/ expanded graphite electrically conducting composite," Composite Interfaces, vol. 11, no. 2, pp. 131-143, 2004.

[11] G.-H. Chen, D.-J. Wu, W.-G. Weng, and W.-L. Yan, "Preparation of polymer/graphite conducting nanocomposite by intercalation polymerization," Journal of Applied Polymer Science, vol. 82, no. 10, pp. 2506-2513, 2001.

[12] W. Zheng and S.-C. Wong, "Electrical conductivity and dielectric properties of PMMA/expanded graphite composites," Composites Science and Technology, vol. 63, no. 2, pp. 225-235, 2003.

[13] X.-M. Chen, J.-W. Shen, and W.-Y. Huang, "Novel electrically conductive polypropylene/graphite nanocomposites," Journal of Materials Science Letters, vol. 21, no. 3, pp. 213-214, 2002.

[14] A. Yu, P. Ramesh, M. E. Itkis, E. Bekyarova, and R. C. Haddon, "Graphite nanoplatelet-epoxy composite thermal interface materials," Journal of Physical Chemistry C, vol. 111, no. 21, pp. 7565-7569, 2007.

[15] C. Lin and D. D. L. Chung, "Graphite nanoplatelet pastes vs. carbon black pastes as thermal interface materials," Carbon, vol. 47, no. 1, pp. 295-305, 2009.

[16] M.-T. Hung, O. Choi, Y. S. Ju, and H. T. Hahn, "Heat conduction in graphite-nanoplatelet-reinforced polymer nanocomposites," Applied Physics Letters, vol. 89, no. 2, Article ID 023117, 2006.

[17] Y. Si and E. T. Samulski, "Exfoliated graphene separated by platinum nanoparticles," Chemistry of Materials, vol. 20, no. 21, pp. 6792-6797, 2008.

[18] Y. Si and E. T. Samulski, "Synthesis of water soluble graphene," Nano Letters, vol. 8, no. 6, pp. 1679-1682, 2008.

[19] D. Li, M. B. Müller, S. Gilje, R. B. Kaner, and G. G. Wallace, "Processable aqueous dispersions of graphene nanosheets," Nature Nanotechnology, vol. 3, no. 2, pp. 101-105, 2008.
[20] M. A. Rafiee, J. Rafiee, Z. Wang, H. Song, Z.-Z. Yu, and N. Koratkar, "Enhanced mechanical properties of nanocomposites at low graphene content," ACS Nano, vol. 3, no. 12, pp. 38843890, 2009.

[21] J. Li, M. L. Sham, J.-K. Kim, and G. Marom, "Morphology and properties of UV/ozone treated graphite nanoplatelet/epoxy nanocomposites," Composites Science and Technology, vol. 67, no. 2, pp. 296-305, 2007.

[22] T. Yokozeki, Y. Iwahori, S. Ishiwata, and K. Enomoto, "Mechanical properties of CFRP laminates manufactured from unidirectional prepregs using CSCNT-dispersed epoxy," Composites A, vol. 38, no. 10, pp. 2121-2130, 2007.

[23] B. C. Ray, "Temperature effect during humid ageing on interfaces of glass and carbon fibers reinforced epoxy composites," Journal of Colloid and Interface Science, vol. 298, no. 1, pp. 111117, 2006.

[24] Y.-K. Choi, K.-I. Sugimoto, S.-M. Song, Y. Gotoh, Y. Ohkoshi, and M. Endo, "Mechanical and physical properties of epoxy composites reinforced by vapor grown carbon nanofibers," Carbon, vol. 43, no. 10, pp. 2199-2208, 2005.

[25] Y. Zhou, F. Pervin, L. Lewis, and S. Jeelani, "Experimental study on the thermal and mechanical properties of multiwalled carbon nanotube-reinforced epoxy," Materials Science and Engineering A, vol. 452-453, pp. 657-664, 2007.

[26] Y. Zhou, F. Pervin, L. Lewis, and S. Jeelani, "Fabrication and characterization of carbon/epoxy composites mixed with multiwalled carbon nanotubes," Materials Science and Engineering A, vol. 475, no. 1-2, pp. 157-165, 2008.

[27] S.-Y. Yang, W.-N. Lin, Y.-L. Huang et al., "Synergetic effects of graphene platelets and carbon nanotubes on the mechanical and thermal properties of epoxy composites," Carbon, vol. 49, no. 3, pp. 793-803, 2011.

[28] V. K. Rangari, T. A. Hassan, Q. Mayo, and S. Jeelani, "Size reduction of WO3 nanoparticles by ultrasound irradiation and its applications in structural nanocomposites," Composites Science and Technology, vol. 69, no. 14, pp. 2293-2300, 2009.

[29] R. M. Rodgers, H. Mahfuz, V. K. Rangari, N. Chisholm, and S. Jeelani, "Infusion of SiC nanoparticles into SC-15 epoxy: an investigation of thermal and mechanical response," Macromolecular Materials and Engineering, vol. 290, no. 5, pp. 423429, 2005.

[30] J. Halpin, "Stiffness and expansion estimates for oriented short fiber composites," Journal of Composite Materials, vol. 3, no. 4, pp. 732-734, 1969.

[31] J. Ashton, J. C. Halpin, and P. H. Petit, Primer on Composite Materials: Analysis, Connecticut: Techno Stamford, 1969.

[32] T. Mori and K. Tanaka, "Average stress in matrix and average elastic energy of materials with misfitting inclusions," Acta Metallurgica, vol. 21, no. 5, pp. 571-574, 1973.

[33] H. L. Cox, "The elasticity and strength of paper and other fibrous materials," British Journal of Applied Physics, vol. 3, no. 3, article 302, pp. 72-79, 1952.

[34] X.-L. Gao and K. Li, "A shear-lag model for carbon nanotubereinforced polymer composites," International Journal of Solids and Structures, vol. 42, no. 5-6, pp. 1649-1667, 2005.

[35] J.-I. Weon, "Mechanical and thermal behavior of polyamide6/clay nanocomposite using continuum-based micromechanical modeling," Macromolecular Research, vol. 17, no. 10, pp. 797806, 2009. 
[36] S. Chatterjee, F. Nafezarefi, N. H. Tai et al., "Size and synergy effects of nanofiller hybrids including graphene nanoplatelets and carbon nanotubes in mechanical properties of epoxy composites," Carbon, vol. 50, no. 15, pp. 5380-5386, 2012. 

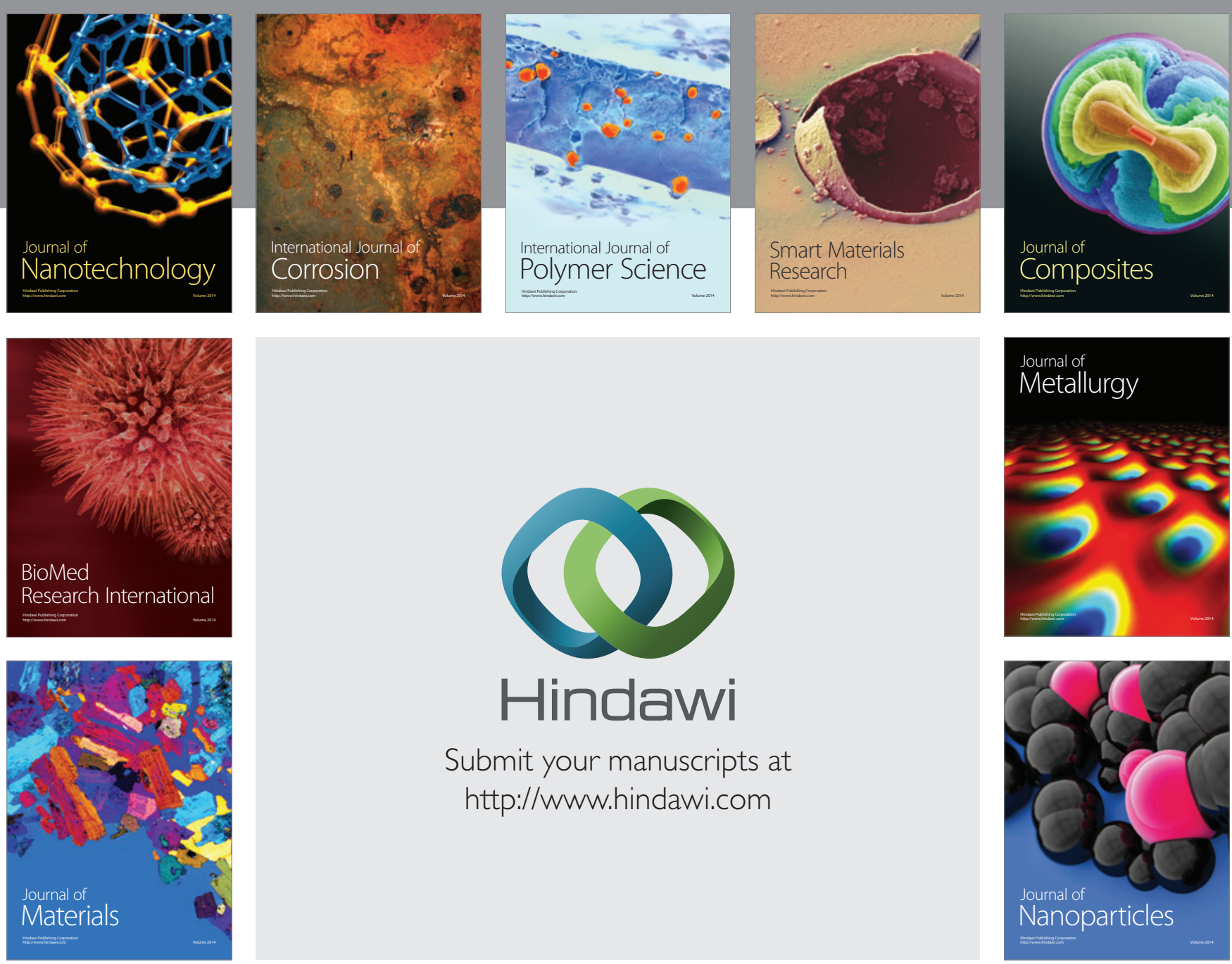

Submit your manuscripts at http://www.hindawi.com
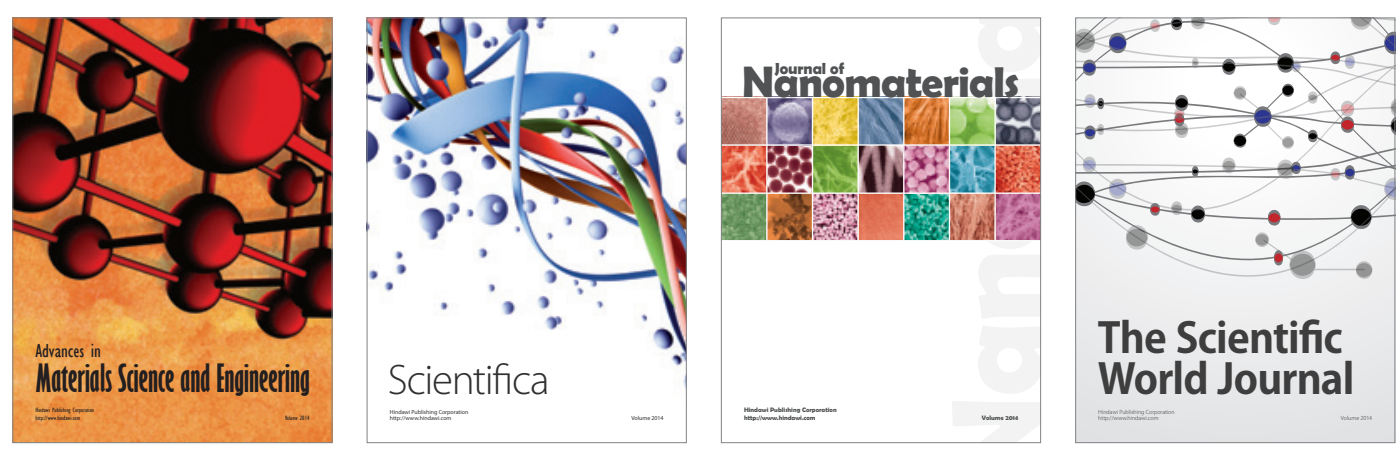

\section{The Scientific World Journal}
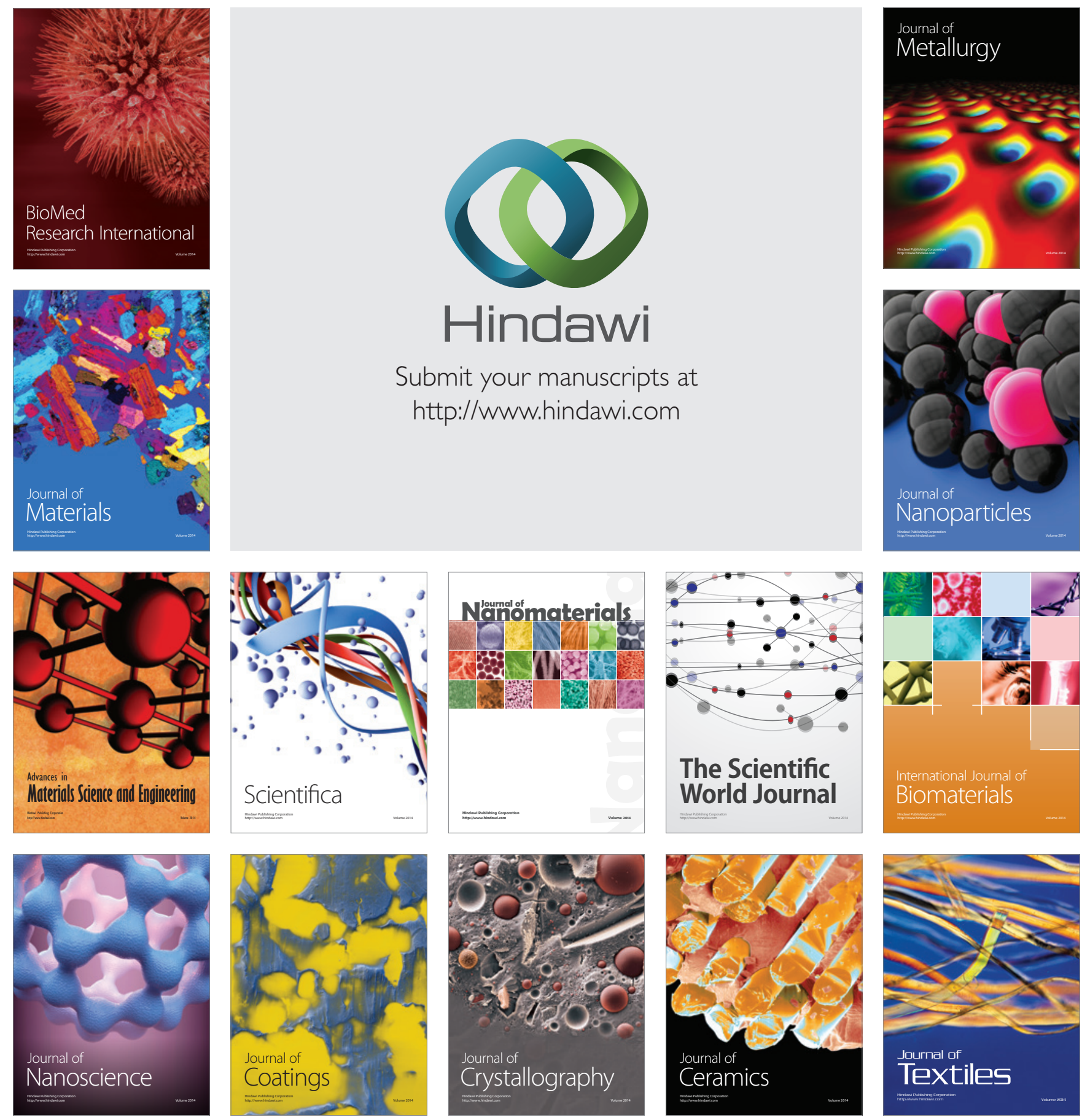